\title{
The Study of International Exhibition's Temporary Cluster Effects on Exhibitor's Realization of Resource Integration Based on the Belt and Road Initiative
}

\author{
Lidan Zhang \\ International Business School \\ Yunnan University of Finance and Economics \\ Kunming, China \\ 393988476@qq.com
}

\begin{abstract}
This paper follows the spotlight of the Belt and Road Initiative, and focuses on the research of the exhibitor's proceedings of resource acquisition from international exhibition by utilizing the theoretical framework of temporary cluster. The study designs an investigation targeting exhibitors of China South Asia Expo, analyzes the exhibitors' fulfillment of resource aggregation, competition cooperation and knowledge spillover under the temporary cluster mechanism of resource integration, and then explores the theoretical explanation of international exhibition's transmission path of economic effect on exhibitors.
\end{abstract}

Keywords - the belt and road initiative; international exhibition; temporary cluster; resource integration effect

\section{INTRODUCTION}

The Belt and Road Initiative leads a new phase of Yunnan's economic development. It upgrades a series of beneficial conditions including geographical convenience, good timing and favorable human relation to Yunnan Province. Geographical convenience, which stems from Yunnan's unique location, is the most appealing strong point. Technically, Yunnan is the only province in China that enables land transportation to both South Asia and Southeast Asia. When looking back to the map of The Belt and Road Initiative, it is easily found that Yunnan is rightly linked to the north of Silk Road. That is why Yunnan is officially named as a Province facing Sanya and taking two oceans on the shoulder. At present, The Belt and Road Initiative has been gradually implemented, which enlarges Yunnan's regional advantage, strategic importance and strength of people-to-people diplomacy. This good news promotes Yunnan's construction of the international transport corridors with neighboring countries, encourages Yunnan's confidence of the Greater Mekong sub regional economic cooperation in a new height, and motivates Yunnan's self establishment as a radiation center confronting South Asia and Southeast Asia. In this sense, Yunnan should take China South Asia Expo as a starting point to fully reach the countries involved in the plan of The Belt and Road and become an important builder of it.
Nevertheless, the academic research of China's exhibition industry, which arising in the year of 1990, is still in the initial stage The late appearance of investigation in China's modern exhibition makes China's previous academic achievements limited in amount and scope. Yang Yong [1], as the representative of most Chinese scholars, only paid attention to study on exhibition's extensive economic and social effects in view of input-output model, but ignore the intermediate proceedings of transferring input into output, as well as the transmission mechanism of exhibition's economic effects on the group of exhibitors. Although a small number of scholars like Wang Xiaowen [2] have tried to reveal the means and paths of transmission, his research object was subject to startup companies, and there was no clear argument to the issue of 'how the exhibition can produce economic effects on exhibitor and what kinds of actions taken are cost-efficient'.

Thus, this article will take the perspective of exhibitor, draw on the research framework of temporary cluster, and investigate China South Asia Expo to illustrate International Exhibition's cluster impact on exhibitor's resources integration.

\section{THE THEORETICAL RELATIONSHIP BETWEEN TEMPORARY CLUSTER AND INTERNATIONAL EXHIBITION}

"Temporary cluster" is the derivation of the word "Cluster". Traditionally, the concept cluster is meant for permanent clusters, which have been defined and studied by different schools and reached a consensus already. With the enhancement of economic globalization, traditional clusters' regional preference and local diversity have been gradually weakened. Instead, the market tends to demand a new form of cluster to effectively put the global resource, workforce and capability all together. Many analysts of economic geography suggested that the economic interactions among members are not confined to the zone of permanent clusters. The parties of cluster begin to break through the border of their cluster, and makes use of the intermediary agencies or outer enterprises to establish a much more widespread social connections. This act will then enable entity in different business zone to bring about 
information transmission, the network building and the knowledge innovation in long distance. However, the fact is that the relationship and trust established among enterprises will increasingly shorten due to the extension of distance. Only through an organized face-to-face communication can enterprises strengthen the sense of trust, which is a right opportunity for the birth of "Temporary cluster" [3].

The concept of "Temporary cluster" was formally put forward by Maskell, Bathelt and Malmberg in 2006 [4]. They defined the temporary cluster as a flow of specialized workforce through different places in a more compact way and relatively shorter time. In spite of the short duration, temporary clusters still can call global elements and business behaviors together, allowing members with similar commercial purpose to get their applicable business partners, fill the knowledge gap and encourage industry innovation.

With the emergence of temporary cluster theory, Malmberg linked "Temporary cluster" with "International exhibition" for the first time. Bathelt [5] pointed out in 2006 that international exhibition is the most significant category of temporary cluster, which is mainly reflected in its worldwide exchange of goods and information in a short period. That is to say the functions of international exhibition are all close to the effects of temporary cluster. International exhibition promotes enterprises to identify their partners from institutions in other regions, develop new trans-regional transactions, and build broader networks. The theoretical relationship between the temporary cluster and the international exhibition has implied the feasibility of research on exhibitors' resource integration of international exhibition from the perspective of temporary cluster.

\section{TEMPORARY Cluster's RESOURCE INTEGRATION EFFECT}

Resources are the basis for the survival and development of enterprises. Since some resources are scarce, enterprises are forced to make resource integration for their optimum allocation. The theory of resource integration is originated from resource-based theory. In 1959, Penrose demonstrated the theory of "Organization's unbalanced growth" and formed the foundation of the resource-based theory. Wernerfelt [6] supported resource-based theory by holding the view business performance is essentially determined by its profile of resource. Thus, high performance is sourced from rare, valuable, hard to copy and non-susbsitituable resources and capabilities.

However, resource-based theory is too much absorbed in utilization of internal resource, ignoring the discussion on obtaining the competitive advantages from external resources. To fill the gap in this field, the theory of resource integration is more likely to emphasize on cluster's role in resource optimization, in order to integrate some other resources from upstream to downstream in industry chain. Cluster's resource integration effect was strongly testified by a considerable number of scholars, and systemized by Zheng Jian [7] who learn from Marshall's study on elements of cluster competitive advantage and shaped cluster's resource integration effect into three dimensions, including resource aggregation, partnership establishment and knowledge spillover, as shown in figure 1.

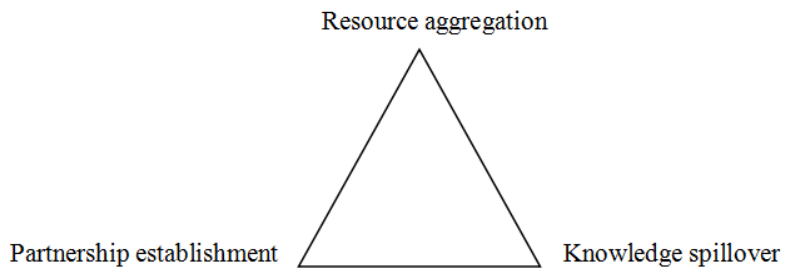

Fig. 1. Three dimensions of cluster's resource integration effect

Resource aggregation means the absorption of around natural endowments and capabilities when the cluster could offer collaborative environment and organizational synergy. Partnership establishment refers to the happenings of competition and cooperation among entities in the industrial chain. The so-called knowledge spillover represents the improvement of cluster member's knowledge level through the transmission of specialized know-how from one to another. These three dimensions set up a theoretical framework of resource integration effect within the cluster, but unfortunately no scholars have utilized these results to further discuss the role of temporary cluster particularly. In this case, international exhibition could be a sensible starting point of extensive study on temporary cluster's resource integration effect.

\section{Study on Resource InTEGRATion EFFECt of ChinA- SOUTH ASIA EXPO}

According to the above theoretical framework of cluster's resource integration effect, this research selects one of most typical international exhibitions in Yunnan, China-South Asia Expo as the investigation target. Data from the third round of China-South Asia Expo in 2015 was collected by survey to make up a case study of temporary cluster's resource integration effect on participating enterprises. The investigation covers exhibitors from China, Southeast Asia and South Asia, a great number of whom are manufacturers and retailer mainly in the fields of light industry and agricultural product processing industry. $47.76 \%$ exhibitors are small enterprises in scale of $10-100$ people, $40.59 \%$ of participating enterprises have 1-5 years' experience in exhibition, and $62.07 \%$ of them engage in exporting to China while $87.27 \%$ exhibitors consider Yunnan as the key foreign market. The structure of the survey's sample seems to be remarkable according to those conditions, so this paper continues to figure out the Expo's resource integration effect on exhibitors in three dimensions including resource aggregation, partnership establishment and knowledge spillover.

\section{A. Assessment of Resource Aggregation}

The resource aggregation of international exhibition is driven by customer demand, capital, labor force and technology. As a form of temporary cluster, both sides of supply and demand in the stadium of international exhibition could effectively overcome the geographic deviation between supplier and buyer. International exhibition offers a best occasion for short meeting, negotiation and interaction so that exhibitors are more likely to touch high quality target customers in the short term. The temporary cluster could then contribute to an efficient concentration and flow of the 
production factors which are eventually transformed into the four measurable achievements of trading volume, sales contracts, technical transfer and venture agreement. In the case of China-South Asia Expo, the effectiveness of resources aggregation is assessed by the gap size between exhibitors' expectations of the above four achievement and their actual deals.

As shown in the statistics of exhibitors' exceptions regarding source aggregation, more than half of company's strongest purpose in China-South Asia Expo is to trade goods. The specific expectation of trade volume are measured in figure 2 that $58 \%$ of exhibitors are supposed to have a medium and large trade volume in the Expo, and only $6.4 \%$ exhibitors express a low expectations for the business growth whose exhibition location is usually not favorable.

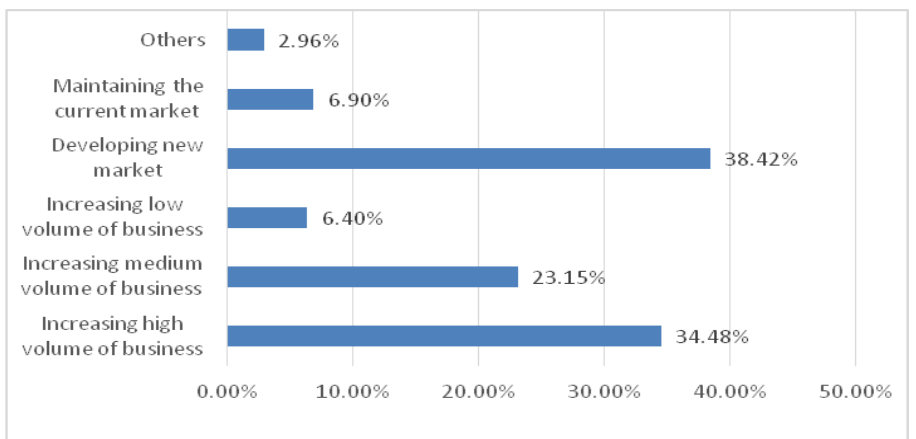

Fig. 2. Exhibitors' exceptions regarding trade volume

When looking at the real status of source aggregation in the Expo, the study detailed the investigation of above four appearances of resource aggregation respectively as shown in figure 3. First, survey of trading volume displays that $46.53 \%$ exhibitors are satisfied with the transactions and $13.37 \%$ merchants cannot reach the expectation. It is worth noting that the trading volume of the jewelry is obviously higher than that of other zones, while the transaction amount of manual painting and national costume is relatively small, revealing the reality that the supply and demand in such area are not matched. Second, the sales contract signed during the Expo are largely praised by exhibitors, leaving $27.64 \%$ of contract deals under the expectation. Third, the evaluation of technical transfer is depressed with only $19.55 \%$ participant succeeding in transfer of technological patents and $40.91 \%$ of the exhibitors failing to take the expected value. Forth, up to $37.25 \%$ exhibitors could not make a consensus with investors, but successful venture agreement still accounts for $25 \%$.

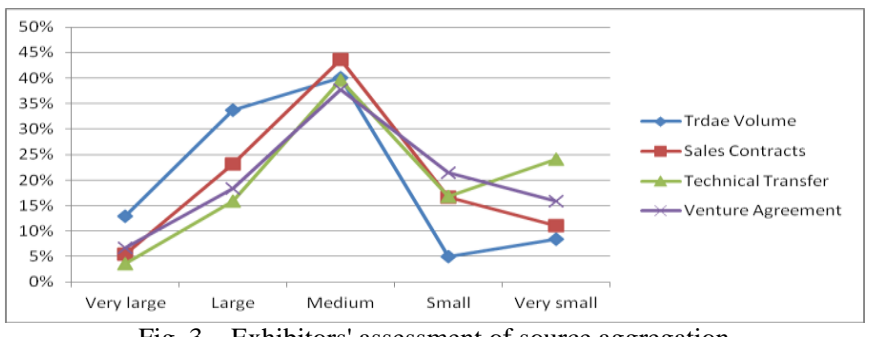

Fig. 3. Exhibitors' assessment of source aggregation

It can be seen that the resource aggregation effect of the South Expo is moderate. In spite of the considerable trading volume, the amount of sales contract, the transfer rate of technological patents and the quantity of investment agreement are not in line with the expectations of the majority of the exhibitors.

\section{B. Assessment of Partnership Establishment}

When designing the criteria of partnership establishment, the study technically tracks the changes of relationships in three groups like "supplier and exhibitor ", "distributor and exhibitor" and "exhibitor and exhibitor" to then identify the exhibitors' willingness and competence to make strategic alliance in China-South Asia Expo.

The investigation found that there are 16\% exhibitors in China-South Asia Expo in serious shortage of building social connections as shown in the figure 4. Being more specific, $32.38 \%$ of exhibitors hold the views that the establishment of supply channels was not remarkable, and the dissatisfied voices are obviously more than the satisfied ones. That means most exhibitors didn't produce a strong partnership with potential suppliers. With regards to the "distributor and exhibitor", the cluster of distributing partners is also unsatisfactory. There are a small number exhibitors in percentage of $27 \%$ optimize their sales network in the Expo, and nearly $29.5 \%$ of the exhibitors think that new distributors and dealers are less than expected and unqualified. Turning to the partnership of "exhibitor and exhibitor", frequency of interactions inside the zone is $12.32 \%$ higher than rate of exchanges outside the zone. $50 \%$ or more exhibitors noted that knowledge of competitors and substitutes tends to be adequate in the Expo, as well as the communication with people in other fields. Apart from "exhibitor and exhibitor", the partnership establishment of "supplier and exhibitor " and "distributor and exhibitor" still remains a weak level in China-South Asia Expo .

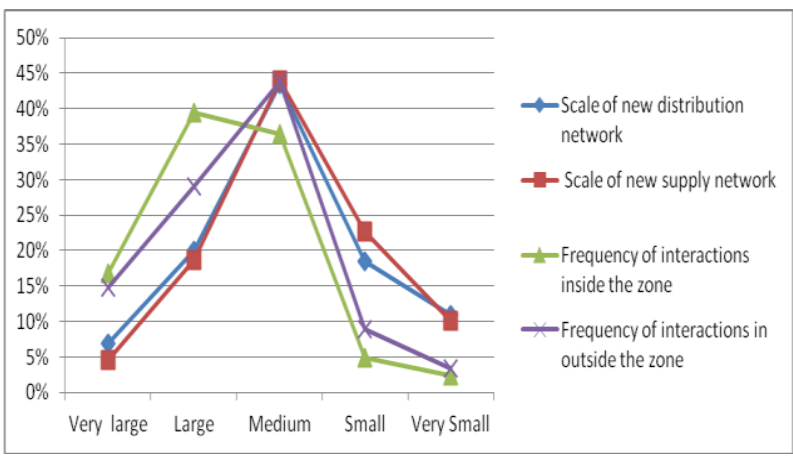

Fig. 4. Exhibitors' assessment of partnership establishment

\section{Assessment of Knowledge Spillover}

The main impacts of knowledge spillovers in temporary clusters could be knowledge innovation, learning ability and communication capability [8]. In China-South Asia Expo, knowledge innovation is generated by exhibitors' mutual absorption of know-how, and it grows in process of informal touch, casual conversation and ordinary transaction. The investigation displays that exhibitors in the Expo have plain performance in acquiring new technology and knowledge. $25.76 \%$ of the exhibitors believe that the number of innovative resources has reached their expectations, but around half of the 
exhibitors are not impressive by others innovation. What is more, $13.13 \%$ of the exhibitors reflected a bad experience of observing new technical outputs in the exhibition. Correspondingly, only $13.86 \%$ of exhibitors assumes to find technological breakthrough in the China-South Asia Expo. All this implies the proportion of innovation-led enterprises is relatively small in the Expo.

The learning ability of temporary clusters could be simply considered as absorptive capacity of knowledge. Similar to modes of knowledge innovation, exhibitors largely depend on conscious and unconscious meeting, customer feedback and regular observation to imitate leading enterprise. It is interesting to see that exhibitors in the Expo have a strong sense of communication, $56.51 \%$ of which favors learn and exchange in the same fields. On the contrary, $43.84 \%$ exhibitors actively seek to get knowledge of their peers in different fields. Attention should be paid to $19 \%$ of the actual technical transfer in the Expo, which explains an inadequate utility of knowledge behind the learning ability.

The above truth reflects that the existence of "path dependence" in knowledge exchange is in terms of information channel of knowledge spillovers. For many temporary clusters, new knowledge must be finally spread to the superior management level of each enterprise. Whether the channel of knowledge diffusion is smooth or not is determined by the carrier of knowledge transfer, the similarity of the inner information structure and the outer ones, and the frequency of inputting new information to original information system. If the participating enterprise of China-South Asia Expo cannot restructure the innovative information effectively with past knowledge, and eventually adopt the combined know-how through the whole enterprises, they will lose the significance of participating in the temporary cluster. Therefore, the knowledge blended process is not an independent matter happened in the exhibition site, but require a continuous offsite diffusion in the exhibitors' all levels of department to truly realize the training and renewal of the core competence.

\section{CONCLUSION}

This article takes a case study of China-South Asia Expo to explore a deep understanding of the mechanism of resource integration in temporary cluster. Meanwhile, the international exhibition's effects of resource aggregation, partnership establishment and knowledge spillover on exhibitors significantly respond to The Belt and Road Initiative's influence on micro-level parties. The founding of the study concludes that the three dimensions of resource integration effect are not synchronous China-South Asia Expo, when knowledge spillover is seriously lagging behind. It could be a strategic highlights for the organizer of China-South Asia Expo. Even though the mechanism of resource integration in China's international exhibition made an initial progress in this study, it is worth noting that China South Asia Expo could not explains other forms of international exhibitions in China. Therefore, it is necessary to further testify the theoretical framework of resources integration effect in other cases of temporary cluster.

\section{ACKNOWLEDGMENT}

This work is supported by Science Foundation of Yunnan Applied Basic Research Project (No. 201601YG00005) and Youth Foundation of Yunnan University of Finance and Economic Research Project (No. YC2014B18).

\section{REFERENCES}

[1] Y. Yang, "Critical Thoughts of Some Basic Issues of Exhibition's Economic Effect," Tourism Studies, vol 10, 2009, pp. 73-82.

[2] X.W. Wang, Y.L. Zhang, and J.N. Wang, "Research on the Mechanism of the Economic Effect of Exhibition Based on Entrepreneurial Activities ," Tourism Science, vol. 25, 2011, pp. 49-57.

[3] L. Liu, and G. Zeng, "Research on International Temporary Cluster Development -- Taking International Exhibition as an Example," World Geography Studies, vol. 21, 2012, pp. 131-138.

[4] P. Maskell , H. Bathelt, and A. Malmberg, "Building Global Knowledge Pipelines: The Role of Temporary Clusters," European Planning Studies, vol. 14(8), 2006, pp. 997-1013.

[5] H. Bathelt, and N. Schuldt, "Between Luminaires and Meat Grinders: International Trade Fairs as Temporary Clusters," Regional Studies, vol. 42(6), 2008, pp. 853-868.

[6] B.Wernerfelt, "The Resource-Based View of the Firm," Strategic Management Journal, vol. 5 (2), 1984, pp. 171-180.

[7] J. Zheng, and X. Li, “ Research on Mechanism in Formation of Cluster's Competitiveness: Theory and Practice," Zhejiang Academy Press, Zhejiang, 2005.

[8] Y.G. Wang, “ The Resource Integration of China's Exhibition from the Perspective of Cluster Effect," Shanghai University of Finance and Economics Press, Shanghai, 2010 